\title{
Spinster Controls Dpp Signaling during Glial Migration in the Drosophila Eye
}

\author{
Yeliz Yuva-Aydemir, Ann-Christin Bauke, and Christian Klämbt \\ Institut für Neurobiologie, Universität Münster, D-48149 Münster, Germany
}

The development of multicellular organisms requires the well balanced and coordinated migration of many cell types. This is of particular importance within the developing nervous system, where glial cells often move long distances to reach their targets. The majority of glial cells in the peripheral nervous system of the Drosophila embryo is derived from the CNS and migrates along motor axons toward their targets. In the developing Drosophila eye, CNS-derived glial cells move outward toward the nascent photoreceptor cells, but the molecular mechanisms coupling the migration of glial cells with the growth of the eye imaginal disc are mostly unknown. Here, we used an enhancer trap approach to identify the gene spinster, which encodes a multipass transmembrane protein involved in endosome-lysosome trafficking, as being expressed in many glial cells. spinster mutants are characterized by glial overmigration. Genetic experiments demonstrate that Spinster modulates the activity of several signaling cascades. Within the migrating perineurial glial cells, Spinster is required to downregulate Dpp (Decapentaplegic) signaling activity, which ceases migratory abilities. In addition, Spinster affects the growth of the carpet cell, which indirectly modulates glial migration.

\section{Introduction}

Any complex nervous system is built of neurons and glial cells. Its correct formation crucially depends on a precise and well orchestrated interaction of these cell types. Whereas neurons often reside at their birthplaces, glial cells migrate over long distances. Thus, glial migration must be carefully matched to the corresponding neuronal substrates (Klämbt, 2009). Glial migration is extensively studied in Drosophila. During embryonic PNS development, glial cells born in the CNS migrate outward along the segmental nerves guided by diffusible signals and differential adhesion (Sepp et al., 2000; von Hilchen et al., 2008, 2010; Silies and Klämbt, 2010). During wing formation, peripherally born glia follow sensory axons as they travel toward the CNS (Aigouy et al., 2004, 2008). In contrast, within the developing visual system, glial cells are born in the CNS and migrate outward to the forming compound eye. Photoreceptor neurons are sequentially generated in the wake of the morphogenetic furrow, which sweeps anteriorly over the eye imaginal disc. Thus, glial migration must be closely coupled to eye disc development (Choi and Benzer, 1994; Rangarajan et al., 1999; Silies et al., 2007, 2010; Franzdóttir et al., 2009).

Received Jan. 27, 2011; accepted March 2, 2011.

This work has been supported through funds from the Deutsche Forschungsgemeinschaft (Sonderforschungsbereich 629) (C.K.). Y.Y-A. acknowledges a fellowship of the Cell Dynamics and Disease graduate program. We thank S. Sweeney for providing spinster alleles and antibodies, and P. J. Dolph, M. González-Gaitán, D. Bilder, P. ten Dijke, and K. Bartscherer for flies and antibodies. Additional antibodies were obtained from the Developmental Studies Hybridoma Bank (lowa City, IA); all general fly stocks were provided by the Bloomington Stock Center (Indiana University, Bloomington, IN). We are thankful to FlyBase for providing information and to M. Silies, and S. R. Franzdóttir for comments on this manuscript and help during the entire project, and H. Aberle, S. Bogdan, T. Hummel, and all members of the Klämbt Laboratory for help and advice in different phases of the project.

Correspondence should be addressed to Christian Klämbt, Institut für Neurobiologie, Universität Münster, Badestrasse 9, D-48149 Münster, Germany. E-mail: klaembt@uni-muenster.de.

DOI:10.1523/JNEUROSCI.0459-11.2011

Copyright $\odot 2011$ the authors $\quad 0270-6474 / 11 / 317005-11 \$ 15.00 / 0$
Only few signaling pathways control neuronal differentiation in the eye disc. The cytokine Unpaired is expressed at the posterior end of the eye disc, where it inhibits Wingless expression and triggers the formation of the morphogenetic furrow (Arbouzova and Zeidler, 2006; Ekas et al., 2006; Tsai et al., 2007). Within the Decapentaplegic (Dpp)-expressing morphogenetic furrow, neurogenesis is initiated. Subsequently, neuronal cells start expressing Hedgehog $(\mathrm{Hh})$, which activates Dpp further anterior and thus pushes the morphogenetic furrow across the epithelium (Treisman and Rubin, 1995). Both Hh and Dpp were also suggested to regulate glial cell development in the eye disc. Initially, Hh prevents precocious glial migration (Hummel et al., 2002); in later stages, Hh stimulates glial proliferation and motility, whereas Dpp induces glial proliferation (Rangarajan et al., 2001).

The identification of different glial cell types in the developing eye imaginal disc provided a first mechanistic model how glial migration and disc maturation is coordinated. Only two subperineurial glial cells, called carpet cells, cover the eye imaginal disc. On these cells, the perineurial glial cells migrate toward the morphogenetic furrow. At the anterior end of the carpet cell, the perineurial glial cells first contact nascent photoreceptor axons, which triggers the differentiation of the wrapping glia (Silies et al., 2007, 2010; Franzdóttir et al., 2009).

Here, we report the analysis of spinster, which affects glial migration onto the eye disc. Spinster mutants show glial overmigration phenotype, which is modulated by genes required for different aspects of endocytotic trafficking. We found increased Dpp signaling in spin mutant glial cells. Accordingly, the spinster mutant phenotype can be suppressed by reducing the Dpp signaling strength specifically in the glia. Our data provide a mechanistic explanation how glial migration and progression of the morphogenetic furrow in the eye disc can be coupled. 


\section{Materials and Methods}

Drosophila work

All Drosophila work was conducted according to standard procedures. Flies were kept at room temperature unless otherwise indicated. The following fly strains were used: spin-Gal4, $\operatorname{spin}^{\Delta 2 \mathrm{~b}}$, UAS-spin-III (Sweeney and Davis, 2002), UAS-spin-I-V flies (Nakano et al., 2001), SPG-Gal4 (Stork et al., 2008), PG-Gal4 (Y. Yuva-Aydemir and C. Klämbt, unpublished results), c527- and Mz97-Gal4 (Hummel et al., 2002), $15 I I a$ (J. Eberhardt and C. Klämbt, unpublished results), da-Gal4 (Wodarz et al., 1995), repo-Gal4 (Sepp and Auld, 1999; Lee and Jones, 2005), elav-Gal4 and ey3.5-Gal4 (FlyBase; Bloomington Stock Collection), the 393 exon trap insertion line was generated in a screen in Münster, Germany (U. Lammel and C. Klämbt, unpublished results), UAS-wgGFP; UAS- $d s h$ (K. Bartscherer, Heidelberg, Germany), Tkv GFP (CPTI-002487; Flannotator). All UASdsRNA flies were obtained from the Vienna Drosophila RNAi Center (Vienna, Austria). Other stocks used in this study were obtained from the Bloomington Stock Center (Indiana University, Bloomington, IN). To generate eye disc clones, FRT42D spin ${ }^{l(2) 10403 /}$ CyO males were crossed to hsflp; FRT42D UbiGFP/Cyo ${ }^{\text {hshid }}$ females. Flies were transferred to a new vial each day and kept at $25^{\circ} \mathrm{C}$. Heat shock was induced at day 2 for $1 \mathrm{~h}$ at $37^{\circ} \mathrm{C}$.

Mosaic analysis with a repressible cell marker analysis. Mosaic analysis with a repressible cell marker (MARCM) analysis was performed as described by Lee and Luo (1999). Glial expressed flp source was used to induce glial clones. Briefly, FRT42D tubPGAL80; repoflp1C, repoactGFP virgin females were crossed to either FRT42D control flies or FRT42D $\operatorname{spin}^{1(2) 10403}$ flies. Larvae were dissected at the late third-instar stage.

Shibire ${ }^{\text {tsl }}$ experiments. UAS-shits ${ }^{\text {ss }}$ flies were crossed to the repo-Gal4 driver. Flies were kept at $25^{\circ} \mathrm{C}$ for $3 \mathrm{~d}$ and were shifted to $31^{\circ} \mathrm{C}$ until the mid-late third-instar larval stage.

Immunohistochemistry and in situ hybridization

Fixation and treatment of tissues for immunohistochemistry was performed as described previously (Stork et al., 2008). All antibodies directed against Drosophila proteins used in this study are known to detect the endogenous expression pattern. Anti-Repo antibodies (Halter et al., 1995; Lee and Jones, 2005) were obtained from the Developmental Studies Hybridoma Bank (Iowa City, IA). Other antibodies used were as follows: anti- $\beta \mathrm{Gal}$ (1:1000; Cappel; MP Biomedicals), anti-green fluorescent protein (GFP) (1:500; Invitrogen), anti- $\beta$-Spectrin (1:250) (Hülsmeier et al., 2007), anti-Spin (1:250) (Sweeney and Davis, 2002) (kind gift from Sean Sweeney, York, UK), anti-Rab5 (1:200; Abcam), anti-Rab7 (1:200) (Chinchore et al., 2009) (kind gift from Patrick J. Dolph, Hanover, PA), anti-Tkv (1:500) (Dudu et al., 2006) (kind gift from Marcos González-Gaitán, Geneva, Switzerland), anti-HRP Cy5 (1:200; Dianova), anti-avl (Lu and Bilder, 2005) (1:500) (kind gift from David Bilder, Berkeley, CA), and anti-phospho-Mad (1:500) (kind gift from Peter ten Dijke, Leiden, The Netherlands). Fluorescently labeled specimens were analyzed using a Zeiss 710 LSM; orthogonal sections were taken using the Zen software of Zeiss. In situ hybridizations were performed with digoxygenin-labeled probes according to standard procedures. LysoTracker Red DND-99 (Invitrogen) in PBS was applied to dissected third-instar larval eye discs (1:500 in PBS). After incubation for $10 \mathrm{~min}$ and several washes, discs were fixed with $4 \%$ formaldehyde and subsequently mounted in Vectashield.
Statistical analysis

To quantify the glial cell number, Repo-positive nuclei in the eye discs were counted using the ImageJ program. The age of the discs was deduced from the number of photoreceptor rows. The Mantel-Haenszel $\chi^{2}$ test was used for all association tests. The change in the frequency of the different glial migration phenotypic classes was compared with the frequency of mutant phenotypes in homozygous $\operatorname{spin}^{P}$ animals.

\section{Results}

Spinster expression in the eye disc glia

Ablation experiments have previously indicated that glial migration onto the eye imaginal disc requires a fully differentiated carpet glial cell (Silies et al., 2007). To identify genes required for the development of this cell type, we screened the expression of enhancer trap lines previously selected for expression in the nervous system (C. Klämbt, unpublished results). Among this collection, the line 15IIa is associated with Gal4 expression in the carpet glia (Fig. 1A). The corresponding transposon insertion was mapped to the first intron of spinster, which encodes a 12pass transmembrane protein localizing to the late endosome or lysosome (Nakano et al., 2001; Sweeney and Davis, 2002; Dermaut et al., 2005) (Fig. 1D). Previously, a genomic DNA fragment upstream of the first spinster exon was used to create a Gal4 

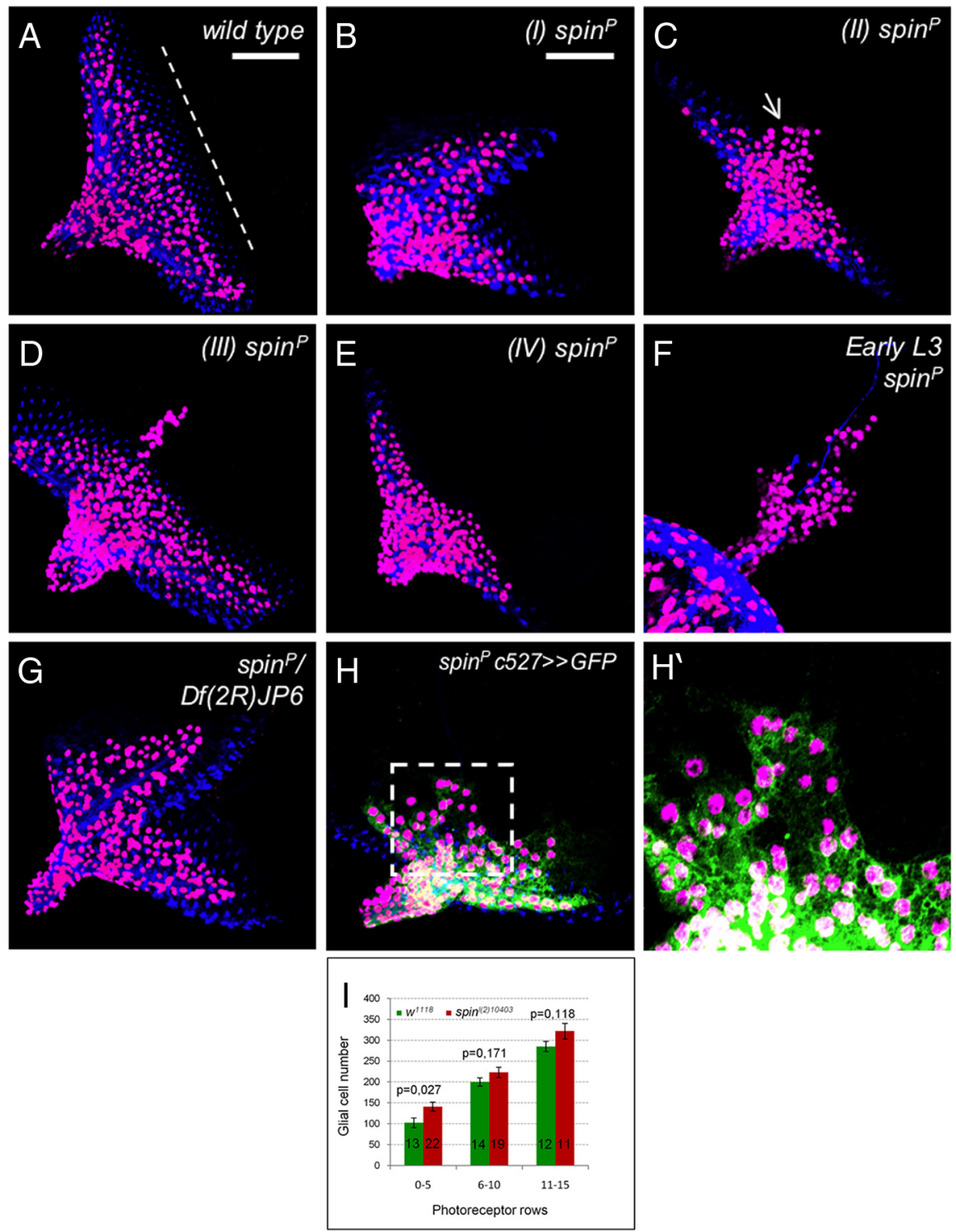

Figure 2. The spinster mutant eye disc phenotype. Third-instar eye imaginal discs stained for Repo (magenta), HRP ( $\boldsymbol{A}-\boldsymbol{H}$, blue), and GFP $\left(\boldsymbol{H}, \boldsymbol{H}^{\prime}\right.$, green). In wild-type larvae, glial cells populate the eye field but stay a few cell rows posterior to the morphogenetic furrow (white dashed line). $\boldsymbol{B}-\boldsymbol{F}$, In homozygous spinster ${ }^{(2) 10403}$ mutant animals $\left(\right.$ spin $\left.^{P}\right)$, several phenotypes can be observed that were grouped into four phenotypic classes. $\boldsymbol{B}$, Class I mutants, A duplication of the eye field $90^{\circ}$ to the normal eye field is observed. Glial cells are spread over the entire disc but are generally associated to neurons. C, Eye discs with a broad stream of glial cells crossing the morphogenetic furrow (arrow) were classified as class II mutants. D, In class III mutants, only a thin stream of glial cells crosses the morphogenetic furrow. Ectopic migration is generally observed along the midline of the eye disc. $\boldsymbol{E}$, In class IV discs, glial cells move close to the morphogenetic furrow and often cross this landmark structure. $\boldsymbol{F}$, The glial migration phenotypes can be observed already in young eye imaginal discs. G, Eye disc morphology defects are observed in spinster ${ }^{J(2) 10403} / D f(2 R) J P 6$ mutant animals. $\boldsymbol{H}_{\boldsymbol{1}} \boldsymbol{H}^{\prime}$, To determine which cell type is affected by the spin mutation, we used the perineurial glial marker $527-\mathrm{Gal} 4$ Almost all ectopic positioned glial cells are perineurial glia. The dotted box in $\boldsymbol{H}$ is shown enlarged in $\boldsymbol{H}^{\prime}$. $\boldsymbol{I}$, Quantification of glial cell number in wild-type and homozygous spinster ${ }^{\mathrm{J}(2) 10403}$ mutant animals. The number of the discs analyzed is indicated on the bars. Error bars indicate SEM. Scale bar, $50 \mu \mathrm{m}$ (all images are taken at the same magnification unless indicated).

driver strain that activates expression of effectors in the endogenous spinster expression pattern (Nakano et al., 2001). When we used this spin-Gal4 element to drive expression, we noted a broader expression pattern. Within the eye imaginal disc, expression is seen in the forming photoreceptor cell clusters and a larger subset of glial cells including the carpet cells (Fig. $1 B, C$ ). Likewise, broad spinster expression can also be detected by antiSpinster antibodies (Fig. $1 E-G$ ). The protein is found in vesicles within neuronal and glial cells (Fig. $1 E, G, G^{\prime}$ ). In spinster mu- tants, the vesicular staining cannot be detected anymore (Fig. $1 F)$.

\section{Spinster affects glial migration in the eye disc}

Given the glial expression pattern, we initiated a phenotypic analysis. The hypomorphic allele $l(2) 10403$ carries an insertion in the first spinster exon (Fig. 1D). Homozygous l(2)10403 animals die as pupae allowing determining the eye disc phenotype. In wild type, glial cells are born in the optic stalk and migrate onto the eye imaginal disc during the third-instar larval stage (Choi and Benzer, 1994; Rangarajan et al., 1999; Silies et al., 2007). Glial cells move until they contact the nascent photoreceptor axons two to four cell rows behind the morphogenetic furrow (Franzdóttir et al., 2009) (Fig. 2A). Homozygous spin ${ }^{l(2) 10403}\left(\operatorname{spin}^{P}\right)$ mutants show several defects in eye disc morphology and glial cell migration. The expressivity of the $\operatorname{spin}^{l(2) 10403}$ mutant phenotypes varies and can be classified according to its severity (Figs. $2 B-E$; 3, line 1). In $9 \%$ of the imaginal discs, we noted a perpendicular duplication of the morphogenetic furrow and the corresponding field of photoreceptor neurons (class I) (Fig. 2B). This phenotype was also seen when $\operatorname{spin}^{l(2) 10403}$ was placed in trans to a chromosomal deficiency covering the spin locus (Fig. 2G). In the majority of the eye discs, the morphogenetic furrow appeared to progress relatively normally across the eye disc epithelium. In $62 \%$ of the discs, glial cells are found anterior to the morphogenetic furrow and appear to migrate in a broad stream onto the eye imaginal disc (class II) (Fig. $2 C$ ). In $11 \%$ of the eye imaginal discs, only a relatively thin stream of glial cells overshoots anteriorly to the morphogenetic furrow (class III) (Fig. 2D). In another 11\% of the eye imaginal discs, we noted an ectopic positioning of glial cells anterior to the position where they are found in wild type (class IV) (Fig. 2E). Finally, 7\% of the homozygous $\operatorname{spin}^{l(2) 10403}$ eye imaginal discs appeared wild type (wt) (data not shown). In general, spinster mutant cell clones contained more glial cells (Fig. 2I). This is in particular apparent in young eye imaginal discs with $0-5$ rows of photoreceptor cells and may indicate increased migration onto the eye disc (Fig. $2 \mathrm{~J}$ ) $(p=0.027)$.

Spinster controls migration of the perineurial glial cells The precise excision of the P-element in $\operatorname{spin}^{l(2) 10403}$ animals reverted all eye disc phenotypes as well as the associated pupal lethality, suggesting that the observed glial cell phenotypes are attributable to disruption of spinster function. The P-element insertion $k 09905$ in the first intron of the gene (Fig. 1D) resulted 
in class II and III glial overmigration phenotypes in homozygosity and class I phenotypes in trans to the deficiency (data not shown). The presumed EMS (ethyl methanesulfonate)-induced null allele $\operatorname{spin}^{11 F 5}$ (which carries an early stop at W114) and $\operatorname{spin}^{\Delta 58}$ both result in early larval lethality and are considered to be null alleles (Flybase, (Dermaut et al., 2005). In trans to $\operatorname{spin}^{l(2) 10403}$, they result in the same range of phenotypes as observed in $\operatorname{spin}^{l(2) 10403} / D f(2 R) J P 6$ animals (data not shown). Thus, the nature of the spinster allele corresponds to the extent of the glial migration defects.

Migration of glial cells can be divided into two distinct phases. During the beginning of the third-instar stage, glial cell migration from the optic stalk to the eye disc is inhibited (Hummel et al., 2002). On initiation of morphogenetic furrow formation, the glial cells migrate on the extending carpet cell onto the eye disc epithelium. The glial cells are never found anterior to the morphogenetic furrow. In spinster mutants, the initial repulsion of glial cells by the eye imaginal disc is disrupted, as already in early third-instar spinster larvae, glial cells migrate far onto the undifferentiated epithelium (Fig. $2 F$ ).

The eye imaginal disc harbors several distinct glial subtypes. To test which glial cell type shows the ectopic migration, we expressed a membrane-linked GFP variant in each glial subpopulation of spinster mutants. The carpet glial cell, as detected by $S P G$-Gal4, was never detected anterior to the morphogenetic furrow. In 2 of 50 cases, we found single $M z 97$-positive wrapping glial cells anterior to the morphogenetic furrow (data not shown). Thus, almost all ectopically migrating glial cells appear to be $c 527$-positive perineurial glial cells (Fig. $2 H, H^{\prime}$ ).

\section{Spinster acts in the migrating glial cells}

Glial migration onto the eye disc is triggered by eye disc-derived signals. To determine in which cell type Spinster is needed for normal glial migration, we first performed cell type-specific rescue experiments using full-length spin isoform-I cDNA under UAS control (spin-I) (Fig. 1D) (Nakano et al., 2001). A weak phenotypic rescue ( $p=0.014)$ is caused by the presence of UASspin-I in the absence of any GAL-4 driver, suggesting that very low levels of spinster expression are sufficient (Fig. 3, line 2).

For ubiquitous expression of spin-I, we used the $d a-G a l 4$ driver, which is expressed in all cells of the animal (Wodarz et al., 1995). da-Gal4 also mediates strong spinster expression in all glial cells (at a stronger level compared with repo-Gal4) (data not shown) and rescues the glial migration and eye disc morphology (Fig. 3, line 3) $(p<0.001)$. In contrast, expression of spin-I in the neurons (elav-Gal4) or in the eye disc epithelium (ey3.5-Gal4) only meliorates the mutant phenotypes, suggesting that spinster is required in glial cells (Fig. 3, lines 4, 5) $(p=0.001 ; p=0.020)$. Indeed, pan-glial expression of spin-I significantly rescues the migration phenotype to an extent comparable with what is observed when we used the spin-Gal4 driver (Fig. 3, lines 6, 7) ( $p<$ 0.001 ). To test which glial cell type is responsible for the mutant spinster phenotype, we performed rescue experiments with c527Gal4 and Mz97-Gal4 driver strains, which drive expression in perineurial and wrapping glial cells, respectively. Both driver lines could mediate a weak phenotypic rescue (Fig. 3, lines 9, 10) ( $p=0.014$ and $p=0.005$ ), whereas expression of spin- $I$ in the subperineurial glial cells using $S P G$-Gal4 did not significantly alter the spinster mutant phenotype (Fig. 3, line 11) $(p=0.044)$. In summary, these rescue data indicate that spinster acts in both the eye imaginal disc and in glial cells to control glial migration.

The gene spinster encodes five alternatively spliced transcripts, type I-V (Fig. 1D) (Nakano et al., 2001). Only pan-glial expression (repo-Gal4) of spin-I and spin-III, which share a common exon 4, rescues the glial migration phenotype. spin-III rescues the glial migration deficits somewhat better than spin-I. We failed to detect any rescue after expression of spin-II or spin $V$ (data not shown). In summary, these data indicate that Spinster carrying a protein domain encoded by exon 4 is required in glial cells to allow normal glial migration during larval development.

\section{Spinster controls glial differentiation}

As mentioned above, ectopic migration in spinster mutants is confined to the perineurial glial cells. However, in the spin mutants, the morphology of the perineurial glial cells does not appear to be altered (Fig. $2 \mathrm{H}, H^{\prime}$ ). To better analyze the function of spinster during glial development, we generated glial specific mutant cell clones by using a repoFlp source as described previously (Silies et al., 2007; Stork et al., 2008). The level of Flp activity is so low that usually only one or two clones are detected in the eye imaginal disc; thus, cell clones originate from a single recombination event. In general, spinster mutant MARCM clones were larger compared with the wild type [six vs nine; $p=0.016$ ( $n=$ 34 wild-type eye discs compared with 50 mutant eye discs; Student's $t$ test)]. Moreover, less wrapping glial cells are found in mutant clones compared with the wild-type clones, whereas the frequency of the perineurial glial cells appeared higher (Fig. 4C,D). The morphology of both cell types appeared nor$\mathrm{mal}$ and no migration phenotypes were evident (data not shown). Only two labeled carpet cells were recovered, and on loss of spinster function, the size of the carpet glia is reduced (Fig. 4, compare $A^{\prime}, B^{\prime}$ ). Similar results were obtained when we silenced spinster function in the different glial populations by using RNA interference (RNAi). Knockdown of spinster function in the perineurial glia (c527-Gal4) using a dsRNA 

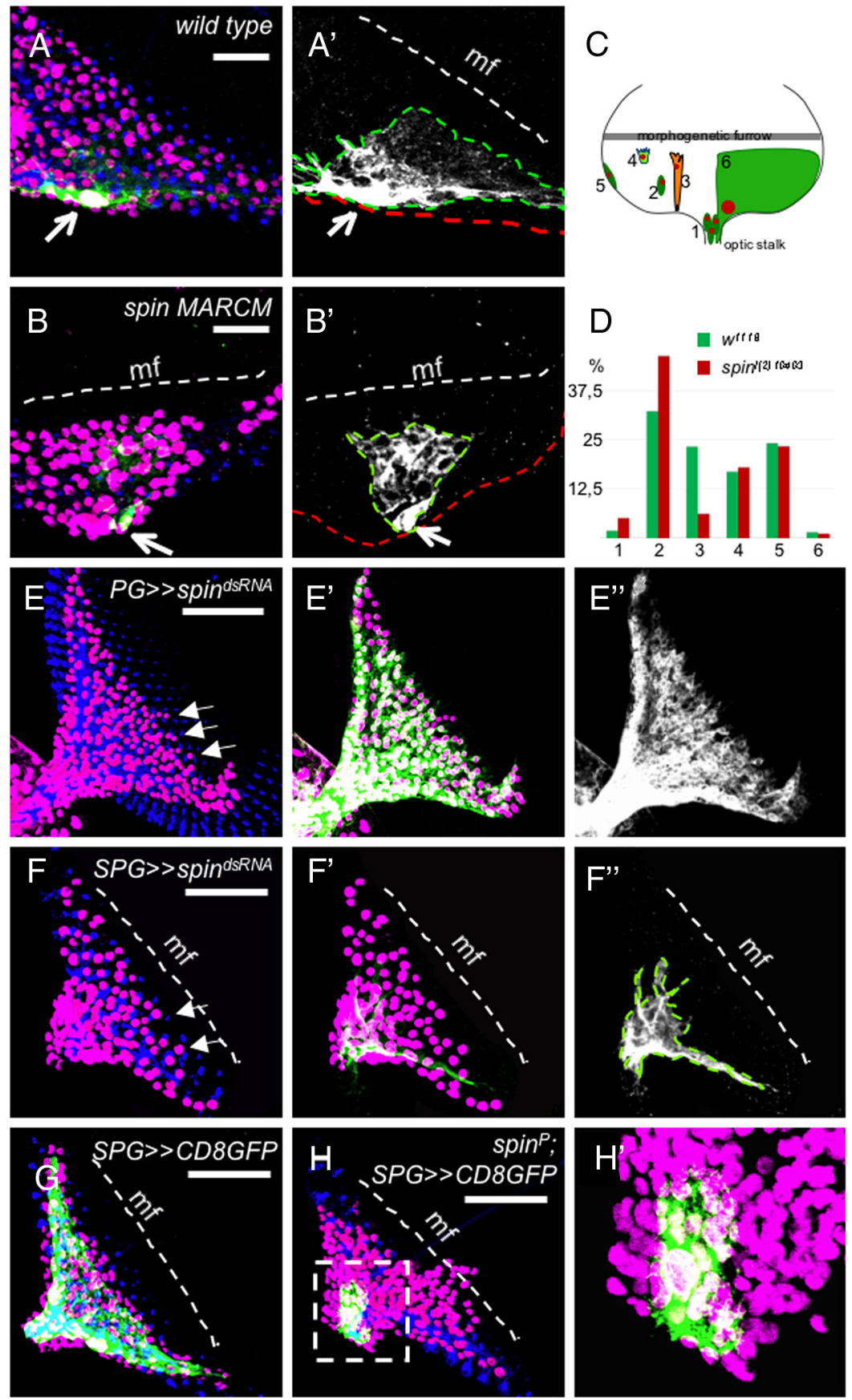

Figure 4. Spinster controls glial differentiation. $A, B$, Examples of MARCM clones of the wild type and $\operatorname{spin}^{1 / 2(2) 10403}$.Clones were induced by repo-flp1C. Glial cell nuclei are in magenta (Repo), neuronal membranes are in blue (HRP), and mutant clones are labeled with the repo-Gal4::UAS-actGFP (green). The white dashed line denotes the morphogenetic furrow ( $\mathrm{mf}$ ). The outline of the carpet cell is indicated by a green dashed line in $\boldsymbol{A}^{\prime}, \boldsymbol{B}^{\prime}$, and $\boldsymbol{F}^{\prime}$. $\boldsymbol{A}, \boldsymbol{A}^{\prime}$, Wild-type carpet glia clone, One carpet glial cell covers the one-half of the posterior eye field. $\boldsymbol{B}$, $\boldsymbol{B}^{\prime}$, A carpet glia in a spin mutant clone is smaller in size. C, Glial cell subtypes in the eye disc are depicted as follows: (1) perineurial glial cells in the optic stalk, (2) perineurial glial cells in the eye disc, (3) wrapping glia, (4) perineurial glial cells at the anterior leading edge, (5) perineurial glial cells at the eye disc margin, and (6) carpet glia. D, The frequency of different glial cell types in the wild type and spin ${ }^{\text {(2) }) 10403}$ mutant clones. Glial cell types are as in $\boldsymbol{C} . \boldsymbol{E}, \boldsymbol{E}^{\prime}, \boldsymbol{E}^{\prime}$, Expression of spin $^{d s R N A}$ in the perineurial glial cells by ${ }^{5} 527-G a l 4$. Some perineurial glial cells migrate ahead of the normally smooth migration front (arrows). $\boldsymbol{F}_{,} \boldsymbol{F}^{\prime}, \boldsymbol{F}^{\prime}$, Downregulation of Spin in the carpet glial cells leads to a significant reduction in the carpet cell size. Note the irregular migration of glial cells at the migration front (arrows). $\mathbf{G}$, Wild-type eye disc with two carpet cells expressing GFP directed by the SPG-Gal4 driver. $\boldsymbol{H}$, Carpet glia in the spin mutant eye discs are very small and do not spread over the entire eye field. $\boldsymbol{H}^{\prime}$ shows the magnification of the selected region (dashed box) in $\boldsymbol{H}$. Scales bars: $\boldsymbol{A}, \boldsymbol{B}, 20 \mu \mathrm{m} ; \boldsymbol{E}-\boldsymbol{H}, 50 \mu \mathrm{m}$.

construct that affects all five isoforms of spinster with no predicted off-targets results in mild migration deficits (Fig. $4 E$, arrows; compare with the smooth migration front in Fig. 4A).

We have previously shown that the carpet glia restricts glial migration in the eye disc and ablation of the carpet glia leads to an early-onset overmigration phenotype (Silies et al., 2007). The morphology of the two carpet glial cells found in each eye disc can be visualized by $S P G-G a l 4$ UASCD8GFP (Fig. 4G). In spinster mutants, the shape of the carpet glia is severely affected and the carpet glia fails to extend over the eye field (Fig. $4 H, H^{\prime}$ ). In general, the extent of carpet glia differentiation correlates with the severity of the glial overmigration phenotype shown in the respective imaginal disc. Knockdown of spinster in the carpet glia using $S P G$ Gal4 results in a reduction of carpet glial cell size that was somewhat less pronounced compared with the spin ${ }^{l(2) 10403}$ mutant (Fig. $4 F$ ). In addition, perineurial glial cells migrated further compared with wild type (Fig. $4 F$, arrows).

In conclusion, these data suggest that, on the one hand, spinster is required within the perineurial glial cells to ensure fidelity of migration. However, spinster is needed within the carpet cell to control its growth over the eye disc. The defective carpet cell in turn contributes to the disrupted perineurial glial migration.

\section{Spinster affects endocytosis}

Spinster is a late endosomal/lysosomal protein, and previous studies showed the accumulation of late endosomes/lysosomes in the spin mutants (Sweeney and Davis 2002). Moreover, the rate of the endosome-tolysosome transfer is reduced in spin mutant garland cells (Dermaut et al., 2005). In spinster mutant eye discs, we noted a dramatic increase of acidic compartments such as late endosomes, and lysosomes dramatically increase in number and size compared with the wild type (Fig. 5A-C). To further characterize vesicle morphology, early and the late endosomes were stained with antibodies against the endocytic syntaxin Avalanche (Avl) ( $\mathrm{Lu}$ and Bilder, 2005) and the GTPase Rab7 (Lu and Bilder, 2005; Stenmark, 2009) (Fig. $5 D, E$ ), respectively. In spinster mutants, early endosomes appear normal, whereas the late endosomes expand in size and form a ring-like structure around the acidic compartments (Fig. $5 E$, arrowhead).

The exact function of Spinster in vesicular trafficking is not known, but it is implicated in the late endosome-to-lysosome transfer or the lysosomal degradation (Sweeney and Davis, 2002). To test whether the glial migration phenotype observed in the spin mutant is linked to defects in the vesicle trafficking, we studied additional gene functions known to be required for the endocytic pathway (Table 1). A ubiquitous knockdown of Eps15, which has a role in the formation of vesicle membranes and hook, which is required for the maturation of 
multivesicular bodies (Sunio et al., 1999), results in glial overshooting in the eye disc. Likewise, the knockdown of Rab7, which affects the late endosome-tolysosome transfer (Vanlandingham and Ceresa, 2009), and Blue cheese (bchs), a lysosomal protein (Simonsen et al., 2007), phenocopies the spin phenotype (data not shown). The fact that only ubiquitous knockdown using da-Gal4 resulted in glial phenotypes may be attributable to insufficient expression levels or it may indicate that expression in both the eye disc and the glial cells is required.

To further test whether endosomal dynamics is required in glia, we assayed whether a change in endosomal dynamics modifies the spin mutant phenotype. The protein hepatocyte growth factor-regulated tyrosine kinase substrate (Hrs) mediates the formation of intraluminal vesicles and maturation of the late endosomes (Lloyd et al., 2002). Reduction of the hrs gene dose in a homozygous spin ${ }^{l(2) 10403}$ background suppresses the spin phenotype, whereas reduction of Rab7 function, which is a key factor in lysosome maturation, under the control of spin-Gal4 appears to increase the phenotypic strength of spinster (Fig. $5 F$ ). Importantly, knockdown of Rab7 in a spinster mutant background resulted in reduced viability, which allowed the analysis of only few eye imaginal discs. These data suggest that spinster controls glial migration by regulating vesicular trafficking, especially transfer through late endosomes to lysosomes in glial cells.

\section{Genetic analysis of spinster function}

spinster likely controls glial migration through an unbalance of protein degradation in the lysosome. Since the activity of several signaling pathways known to be required for glial migration is affected by the sorting of membrane receptors and ligands into different endosomal compartments (Fischer et al., 2006), we assayed their potential interaction with Spinster. Recently, we could show that the eye disc glia expresses the FGF receptor Heartless ( $\mathrm{Htl}$ ) whose activation is pivotal in controlling glial development (Franzdóttir et al., 2009). However, no change in $\mathrm{Htl}$ expression level or localization is detected in spinster mutants nor did we detect changed MAPK (mitogen-activated protein kinase)/[ERK (extracellular signal-regulated kinase)] phosphorylation in spinster MARCM clones (data not shown). Likewise, gene dose experiments did not reveal any genetic interaction between $h t l$ and spinster. We also did not observe any interaction with components of the JAK (Janus kinase)/STAT (signal transducers and activators of transcription) signaling pathway [Domeless (Dome) and Unpaired (Upd)] (Fig. 6A, lines 5, 6).

Hedgehog $(\mathrm{Hh})$ mediates signaling through the membranebound receptor, Patched (Ptc), which is expressed by differentiating glial cells (Hummel et al., 2002; Murakami et al., 2007). Moreover, $h h$ mutants were shown to cause precocious migration of glial cells into the eye disc (Hummel et al., 2002), suggesting that spin and $h h$ might genetically interact. However, a reduction of the ptc gene dose by $50 \%$ (or $h h$ ) in a homozygous spinster mutant background only slightly suppressed the glial overmigration phenotype (Fig. 6A, lines 2,3).

The reduction of wingless $(w g)$ significantly suppressed the spinster glial phenotype (Fig. 6A, line 4). However, glial specific silencing of several components of the wingless signaling pathway [Frizzled and disheveled (dsh)] did not cause any glial migration phenotype (data not shown). Glial-specific activation of wingless signaling by repo-Gal4 driven overexpression of Disheveled (Penton et al., 2002) resulted in fewer glial cells, which migrate normally (data not shown). In contrast, panglial expression of Wingless blocked migration into the eye disc but did also affect neuronal development in the eye disc, suggesting that wingless acts within the eye imaginal disc to control glial migration (data not shown). A prominent candidate mediating this effect is Dpp whose expression in the eye disc is closely connected to wingless activity.

\section{Enhanced Dpp signaling in spinster mutants}

Endocytosis and lysosomal degradation can affect Dpp signaling pathway through regulating both the Dpp morphogen gradient and the turnover. In the Drosophila neuromuscular junction, spinster mutants cause synapse overgrowth, which can be suppressed by reducing the function of the Dpp receptors, Thickveins (Tkv), Saxophone (Sax), and Wishful thinking (Wit) (Sweeney and Davis, 2002). In addition, glial cell migration in the Drosophila eye imaginal disc is affected by Dpp signaling (Rangarajan et al., 2001).

Indeed, the reduction of Dpp levels in a spinster mutant background led to a rescue effect (Fig. 6A, lines 8, 9). Moreover, reduction of mad, which encodes a transcription factor downstream of Dpp receptors, efficiently suppresses the glial overmigration associated with spinster mutants (Fig. 6A, line 7; D). 
Table 1. Genes involved in vesicle trafficking and their effect on glial cell migration in the eye imaginal disc

\begin{tabular}{|c|c|c|c|c|}
\hline UAS & da-Gal4 & ey3.5-Gal4 & repo-Gal4 & Mutant \\
\hline $\mathrm{shi}_{\mathrm{ts} 1}$ & Early lethal & Glial overmigration & Glial overmigration & ND \\
\hline $\mathrm{chc}_{\mathrm{ds} \mathrm{RNA}}$ & Early lethal & No eye disc & Early lethal & Early lethal \\
\hline Eps15 dsRNA & Glial overmigration & ND & Wild type & ND \\
\hline $\mathrm{hrs}_{\mathrm{dsRNA}}$ & Early lethal & ND & Fewer glial cells at $29^{\circ} \mathrm{C}$ & $\begin{array}{l}h r s_{D 28} \\
\text { Early lethal }\end{array}$ \\
\hline hook $_{\text {dsRNA }}$ & Glial overmigration & Wild type & Wild type & $\begin{array}{l}\text { hook }_{1} \\
\text { Glial overmigration }\end{array}$ \\
\hline Vps $25_{\text {dsRNA }}$ & Wild type & ND & Wild type & ND \\
\hline Vps16 $6_{\mathrm{dsRNA}}$ & Early lethal & ND & Early lethal & ND \\
\hline Rab7 $7_{\text {dsRNA }}$ & Glial overmigration & Wild type & Wild type & ND \\
\hline bchs $_{\text {dsRNA }}$ & Glial overmigration & ND & Wild type & ND \\
\hline Rab11 $1_{\text {dsRNA }}$ & Wild type & ND & Early lethal & ND \\
\hline orange $_{\mathrm{dsRNA}}$ & Wild type & Wild type & Wild type & $\begin{array}{l}\text { orange }_{49 h} \\
\text { Wild type }\end{array}$ \\
\hline ruby $_{\text {dsRNA }}$ & Wild type & Wild type & Wild type & $\begin{array}{l}\text { ruby } \\
\text { Wild type }\end{array}$ \\
\hline
\end{tabular}

UASdsRNA or dominant-negative constructs were expressed using the Gal4 driver strains indicated. Crosses were done at $25^{\circ} \mathrm{C}$; for shits1 expression, see Materials and Methods. ND, Not determined.

A

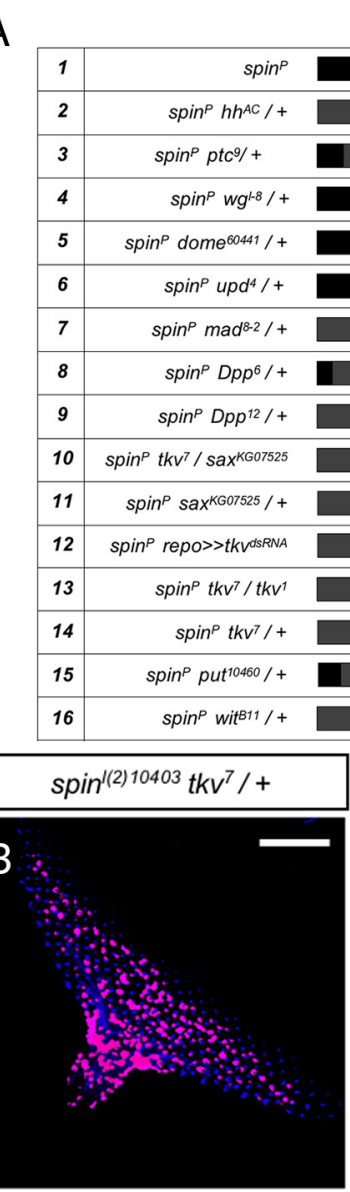

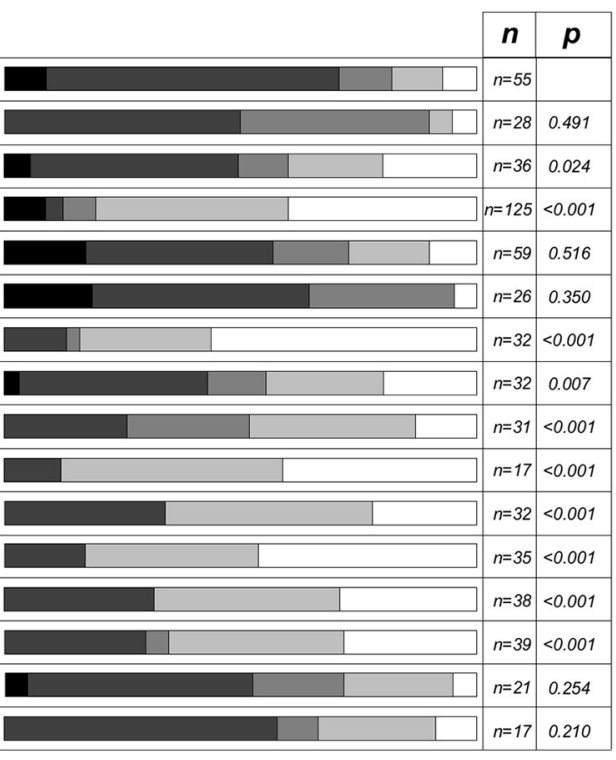

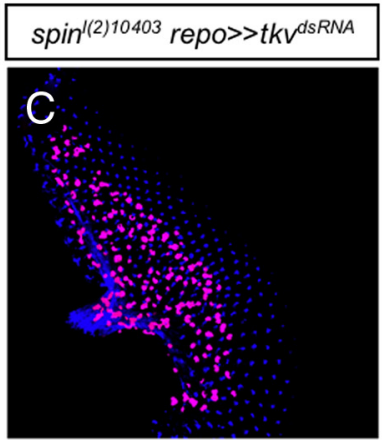

$\operatorname{spin}^{1(2) 10403} \operatorname{mad}^{8-2} /+$

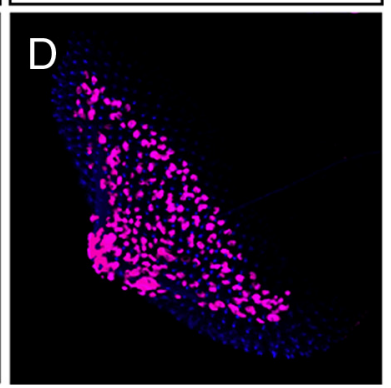

Figure 6. Dpp signaling pathway mutants suppress the glial overmigration phenotype in the spin mutant eye discs. $A$, Genetic analysis of the interaction of spinster ${ }^{/(2) 10403}\left(\right.$ spin $\left.^{P}\right)$ with different signaling pathways. The genotype, the number of eye discs analyzed, and the statistical significance are indicated. $\boldsymbol{B}-\boldsymbol{D}$, Third-instar larval eye discs stained for Repo expression (magenta) and HRP antibody (blue). $\boldsymbol{B}$, Heterozygous $t k v^{7}$ mutation in the spin mutant background rescues the migration defect. C, Downregulation of the tkv only in the glial cells suppresses the spinster glial overmigration phenotype. $\boldsymbol{D}$, Heterozygous mad $^{8-2}$ suppresses the spin phenotype. Scale bar, $50 \mu \mathrm{m}$.

Heterozygous mutations of the type II Dpp receptors wit and put and the type I Dpp receptors tkv and sax have no effect on glial cell migration (data not shown). Reduction of the gene dose of wit and put mutations does not modify the glial over- migration phenotype associated with homozygous spinster mutants, whereas reducing the level of $t k v$ and sax leads to a significant suppression of the mutant phenotype. Moreover, downregulation of $t k v$ function only in the glial cells using a UAStk $v^{d s R N A}$ construct has even stronger rescuing abilities (Fig. $6 A$, lines $10-16 ; B, C)$. In summary, these data demonstrate that, in spinster mutants, enhanced Dpp signaling is causing the glial overmigration phenotype.

Increase in Mad phosphorylation in spin mutant glial cells

We next determined Dpp expression in $s p i n^{\Delta 2 b} / D f(2 R) J P 6$ eye discs using a $d p p-$ lac $Z$ enhancer trap. The $d p p$-lacZ shows specific signal at the morphogenetic furrow in the wild-type discs mimicking endogenous $d p p$ expression (Flybase). In spinster mutants, additional expression at the lateral edge and at the dorsoventral midline is detected (Fig. $7 A, B, D, E$ ). To assay whether glial cells express the Tkv receptor required to detect the different levels of Dpp expression, we used a GFP exon trap insertion (kindly provided by Flannotator). The GFP-tagged Tkv is expressed prominently in the eye disc proper (Fig. $7 C, C^{\prime}$ ). Within the glial cell layer, Tkv expression is found only in the perineurial glial cell layer (Fig. 7C).

In the canonical Dpp signal transduction pathway, the type II receptor phosphorylates the type I receptor, which in turn recruits and phosphorylates the transcriptional coactivator Mad. Thus, phospho-Mad staining can be used as a readout of $D p p$ signaling, which is one of the master signaling pathways that directs eye disc patterning (Affolter and Pyrowolakis, 2006). In wild-type eye discs, phospho-Mad is detected in the morphogenetic fur- 
row and in an anterior domain (Fig. $8 A)$. No phospho-Mad is detected in glial cells (Fig. 8C,E). In spinster mutants, the intensity of the phospho-Mad signal at the morphogenetic furrow is slightly increased when compared with wild type, and the phospho-Mad-positive domains appear enlarged and ectopic signal is detected at the lateral edge of the disc (Fig. $8 B)$. In addition to the eye disc expression, we detect robust phospho-Mad expression in many glial cells in the eye disc and the optic stalk. Only the outermost glial cells, the perineurial cells, express phospho-Mad (Fig. 8D). The carpet cell does not express phospho-Mad in spinster mutants (Fig. $8 F$, asterisk).

In summary, spinster mutants show increase Dpp expression in the eye disc, which translates to increased Dpp activity in the retinal glial cells as seen by the increase of phospho-Mad expression.

\section{Accumulation of Tkv in glial cells}

The genetic interaction data and the increase in phospho-Mad expression in glial cells suggest that Spinster antagonizes Dpp signaling. Spinster, which localizes to the late endosome/lysosome, may downregulate Dpp signaling by stimulating trafficking and lysosomal degradation of activated Dpp receptors. In wild-type eye discs, Tkv localizes in a large vesicular structure in photoreceptor neurons (data not shown). In the spinster mutants, additional Tkv expression spots were detected in photoreceptor cells (data not shown). The increase of Tkv expression was also noted in the eye disc glia and within homozygous mutant cell clones (data not shown).

To determine the nature of the Tkvexpressing vesicular structures, we used the GFP exon trap insertion 393. In this line, GFP expression is found on Rab5-negative but Rab7-positive endosomes (Fig. 7F, G). In wild-type eye discs, Tkv is not localized in 393-expressing vesicles (Fig. 7H). However, in spinster mutants, 393-positive endosomes develop large, ring-like structures surrounding the Tkv signal (Fig. 7I). In summary, in spinster mutants, we note an accumulation of the type I Dpp receptor Tkv in late endosomes. The increase in Dpp receptor expression results in an increase of Dpp signaling since reduction of $t k v$ activity rescues the glial migration phenotype of spinster mutants.

\section{Discussion}

During development of the nervous system, glia cell migration is tightly regulated in time and space. Here, we have demonstrated that, within the Drosophila visual system, glial migration requires the late endosomal/lysosomal protein Spinster to restrict a migratory stimulus provided by Dpp signaling. Spinster is crucially involved in the coordination of eye disc growth and glial migration (Fig. 9). In spinster mutant eye discs, late endosomes accumulate and a glial overmigration phenotype develops. This migration phenotype can be modified by reducing the early to
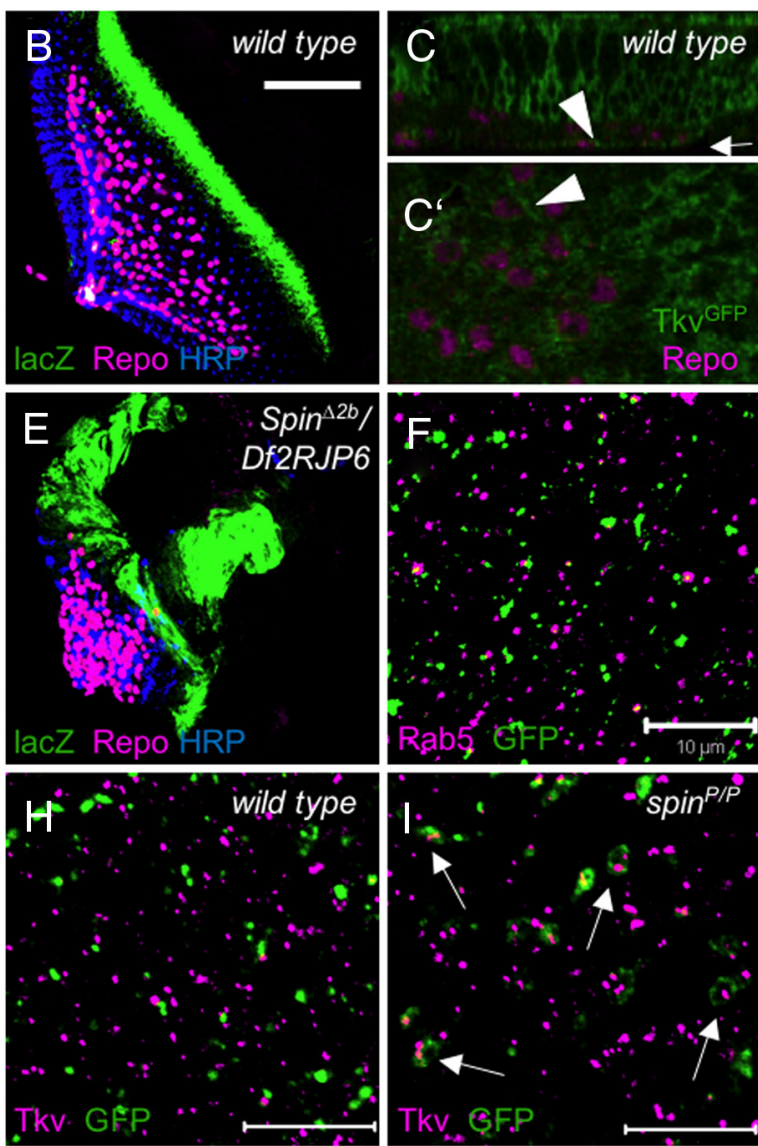

Figure 7. Accumulation of the Tkv in the late endosomes in spin mutant eye discs. $\boldsymbol{A}, \boldsymbol{D}, \mathrm{RNA}$ in situ hybridization using Dpp cDNA the basal-most position as indicated by the arrow in C Note the polar distribution of Tkv expression in glial cells (arrowhead). $D$ In spinster mutants, Dpp expression levels are increased correlating with the disc overgrowth phenotype. $\boldsymbol{E}$, Dpp-lacZ expression in a seen G In contrast, Rab7 (magenta) and 393-directed GFP expression (green) colocalize in many vesicles (white) $\boldsymbol{H}$, In a wild-type background, Tkv (magenta) is localized to late endosomes marked by the $393 \mathrm{GFP}$ trap (Green). I, In a spinster mutant background, 393 GFP expression forms a ring-like structure around Tkv (arrows). Scale bars: $\boldsymbol{A}, \boldsymbol{B}, 50 \mu \mathrm{m} ; \boldsymbol{F}-\mathbf{I}, 10 \mu \mathrm{m}$.

late endosomal transfer or late endosome-to-lysosome transfer through decreasing the levels of hrs. Moreover, the Dpp receptor Thickveins accumulates in spinster mutant cells. Thus, Spinster appears to antagonize Dpp signaling by facilitating the routing of Dpp receptors toward the lysosome (Fig. 9E,F).

Retinal glial cells are born in the CNS and migrate onto the eye disc through the optic stalk (Choi and Benzer, 1994). A reverse migratory direction is taken by the photoreceptor cell axons, which are born in the periphery and navigate toward the brain through the optic stalk (Meinertzhagen and Hanson, 1993; Wolff and Ready, 1993). Peripheral glial cells generally follow axonal growth cones during their migration phase (Klämbt, 2009), and thus within the developing Drosophila visual system, glial cells have to be guided to the nascent photoreceptor axons by other means. In Drosophila, this is accomplished by the carpet cells, very large subperineurial cells that cover the entire eye field (Silies et al., 2007). The carpet cell shields the navigating axons within the stalk from the proliferating and migrating glial population (Fig. 9C). At the beginning of eye imaginal disc development, the carpet cell prevents precocious migration of glial cells onto the eye disc in a process requiring early eye patterning genes and 

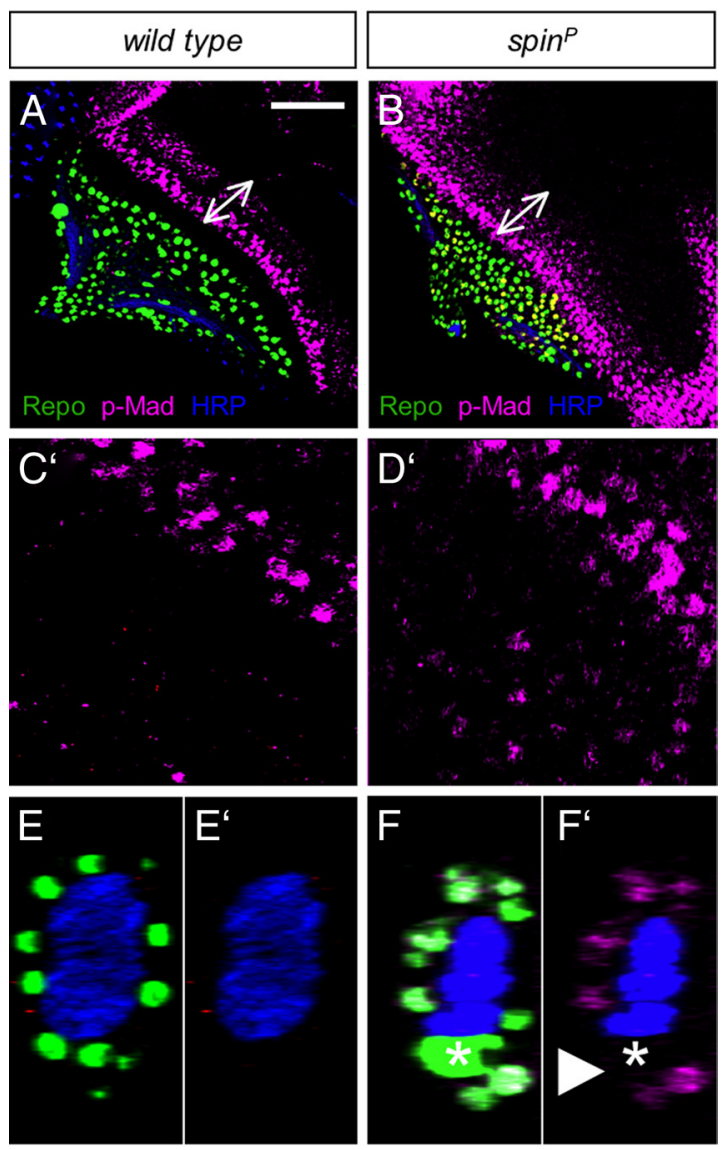

Figure 8. Enhanced Dpp signaling in the spin mutant eye discs. Third-instar larval eye discs stained for Repo expression (green), phospho-Mad (p-Mad) antibody (magenta), and HRP antibody (blue). Wild-type and spinster mutant eye discs were stained in the same staining batch and scanned at the same LSM settings. $\boldsymbol{A}$, In wild-type discs, two stripes of p-Mad signal are seen at the morphogenetic furrow. $\boldsymbol{B}$, In spin mutants, the range of the $p$-Mad signal does not change but the intensity is increased (arrow). $\boldsymbol{C}^{\prime}$, Enlarged view of discs. In the wild type, no p-Mad signal is seen in the glial cells. $\boldsymbol{D}^{\prime}$, In spin mutants, p-Mad signal can be easily detected in glial cells. $\boldsymbol{E}-\boldsymbol{F}^{\prime}$, Orthogonal view in the optic stalk. Increased p-Mad signal is detected in the spin mutant glial cells in the optic stalk. No increase is seen in the nucleus of the carpet cell, which can be recognized by its large size (asterisk). $\boldsymbol{A}-\boldsymbol{F}$, p-Mad, Repo, and HRP staining. $\boldsymbol{C}^{\prime}-\boldsymbol{F}^{\prime}, \mathrm{p}$-Mad and anti-HRP staining. Scales bars: $\boldsymbol{A}, \boldsymbol{B}, 50 \mu \mathrm{m} ; \boldsymbol{C}-\boldsymbol{E}, 10 \mu \mathrm{m}$.

Hedgehog signaling (Hummel et al., 2002). Ablation of the carpet glia as well as disruption of, for example, early Hedgehog signaling result in an overshooting glial migration (Silies et al., 2007). As soon as the morphogenetic furrow is initiated, the carpet glial cell starts to grow and extends anteriorly. However, the carpet cell never reaches the morphogenetic furrow but stops to grow at a few cell rows behind where nascent photoreceptor cell axons are formed. Piggybacking on the carpet cell are the perineurial glial cells that migrate toward the anterior edge of the carpet cell. As soon as they come in contact with photoreceptor axons, they drop from the carpet cell and now follow the sensory axon toward the brain. Thus, two distinct phases of glial cell migration can be defined. Initially, the carpet cell prevents precocious migration, whereas in later phases of eye imaginal disc development the carpet cells provide a permissive substrate for the migrating perineurial glia.

Spinster is involved in the regulation of both of these migratory phases and helps to coordinate the growth of the eye disc with the migration of glial cells. The most dramatic consequences of spinster mutants as seen in eye disc duplications are presumably attributable to effects on Wingless and Dpp within the eye disc. The broad glial overshooting phenotypes correlate with a failure of the carpet cell to prevent early-onset, precocious glial migration. The later glial overmigration phenotypes correlate with late, carpet cell-independent, defects in the perineurial glia. Thus, it is not surprising that, in contrast to panglial expression of Spinster, glial cell type-specific expression is not able to rescue the spinster overmigration phenotype (Fig. 3, line 7).

The size of the carpet glial cell is reduced in spinster mutants, and MARCM analysis as well as cell type-specific RNAi experiments indicate that spinster controls carpet cell growth cell autonomously. Directed expression of Hid or RicinA specifically in carpet cells resulted in a reduced cell size and a concomitant induction of ectopic glial cell migration (Silies et al., 2007). In contrast, single spinster mutant carpet cells did not lead to a glial migration defects, suggesting that the reduced carpet cell only contributes to the glial overmigration phenotype. How spinster controls the size of the carpet cells is currently unknown. Possibly, within the carpet cell, spinster acts via hedgehog signaling. Hedgehog bound to the Patched receptor is normally internalized and degraded in lysosomes (Chen and Struhl, 1996; González-Gaitán, 2003; Torroja et al., 2004). Moreover, Patched is expressed in glial cells (Hummel et al., 2002) and Hh signaling was suggested to prevent precocious glial cell migration through a yet-unknown pathway (Rangarajan et al., 2001; Hummel et al., 2002). However, mutations in different hedgehog signaling components did not suppress the spinster phenotype and inhibition of hedgehog signaling in glial cells did neither alter the morphology of the carpet glia nor did they affect glial migration. Likewise, activation of Hedgehog signaling through expression of PKA ${ }^{\text {dsRNA }}$ did not influence glial migration.

Within the carpet cells, Spinster most likely does also not act through altered Dpp signaling, since no phospho-Mad expression was detected in the carpet cells. In contrast, we noted enhanced Dpp signaling (Mad phosphorylation) in the migrating perineurial glial cells. The analysis of additional mutations affecting different aspects of intracellular vesicle dynamics revealed the importance of endocytic processes in TGF- $\beta$ signaling. The block of Rab5 function causes a reduction in the range of Dpp target gene activation, and Rab5 overexpression causes increased Dpp signaling range (Entchev et al., 2000). Hrs, a component of ESCRT complex, has been shown to interact with Smad2 and participates in the recruitment of Smad2 to the activated receptor (Miura et al., 2000). Hrs seems to be involved in the constitutive ligand-independent receptor turnover since $T \mathrm{kv}$ accumulates at the cell membrane even in the absence of Dpp (Jékely and Rørth, 2003). Hrs downregulation suppresses the spinster glial overmigration, possibly by inhibiting Tkv internalization and accumulation in the endosomes. Within the cell, endosome-to-lysosome transfer and subsequent lysosomal degradation also affects Dpp signaling. Enhanced degradation caused by expression of activated $R a b 7$ reduces the Dpp signaling range, whereas the inhibition of lysosome function with chloroquine leads to an endosomal accumulation of ligands (González-Gaitán, 2003). In addition, pan-glial expression of a dominant-negative Tkv receptor, $t k v^{\Delta G S}$ or $t k v^{d s R N A}$, resulted in reduced glial migration and fewer glial cells (data not shown). Similar results were obtained when we silenced put or mad expression using RNA interference, demonstrating that the regulation of Dpp signaling via controlling vesicle dynamics is required in glial cells to ensure normal proliferation and migration.

Endocytosis and vesicle recycling is generally required in migrating cells to dynamically remodel their adhesive contacts 
and locate active signaling receptors to the front of the cell in response to extracellular signals (Ulrich and Heisenberg, 2009). Integrins from the cell rear can be relocalized to the leading edge, and during border cell migration in the Drosophila ovary, spatial restriction of the receptor tyrosine kinase signaling by endocytosis ensures the localized intracellular response to guidance cues (Jékely et al., 2005; Ezratty et al., 2009). Likewise, glial migration in the embryonic Drosophila PNS is regulated by the fine-tuning of Notch signaling by Numb-mediated endocytosis (Edenfeld et al., 2007). Thus, endocytotic trafficking may affect cell migration through several pathways.

In spin mutants, enhanced Dpp signaling is also observed in the eye imaginal disc and the most extreme eye disc phenotype appears as to be an induction of an ectopic morphogenetic furrow perpendicular to the normal furrow. Ectopic expression of the Dpp in the eye disc or expression of activated Tkv in the glial cells increases glial cell proliferation (Rangarajan et al., 2001). In spin mutants, both increased Dpp expression and accumulation of Tkv are observed. Since spin controls glial cell proliferation cell autonomously, this is likely attributable to the accumulation of Tkv in glial cells. In addition, enhanced Mad phosphorylation is observed in spin mutants, especially in the optic stalk glia. In agreement with this, the increase in glial cell number is mostly noted in the optic stalk. Interestingly, the function of spinster in controlling glial differentiation is also required in the wrapping glia. Loss of spinster results in a reduced wrapping of axonal membranes, which can be rescued by reexpression of spinster in the wrapping glia (Y. Yuva-Aydemir. and D. Engelen, unpublished results). Thus, spinster function appears to be needed to extend cellular processes during migration and differentiation.

In conclusion, Spinster affects glial migration on two different levels. Spinster regulates carpet glia differentiation, which indirectly affects early migration, and subsequently, Spinster acts in the perineurial glia to confer a general cell motility signal.
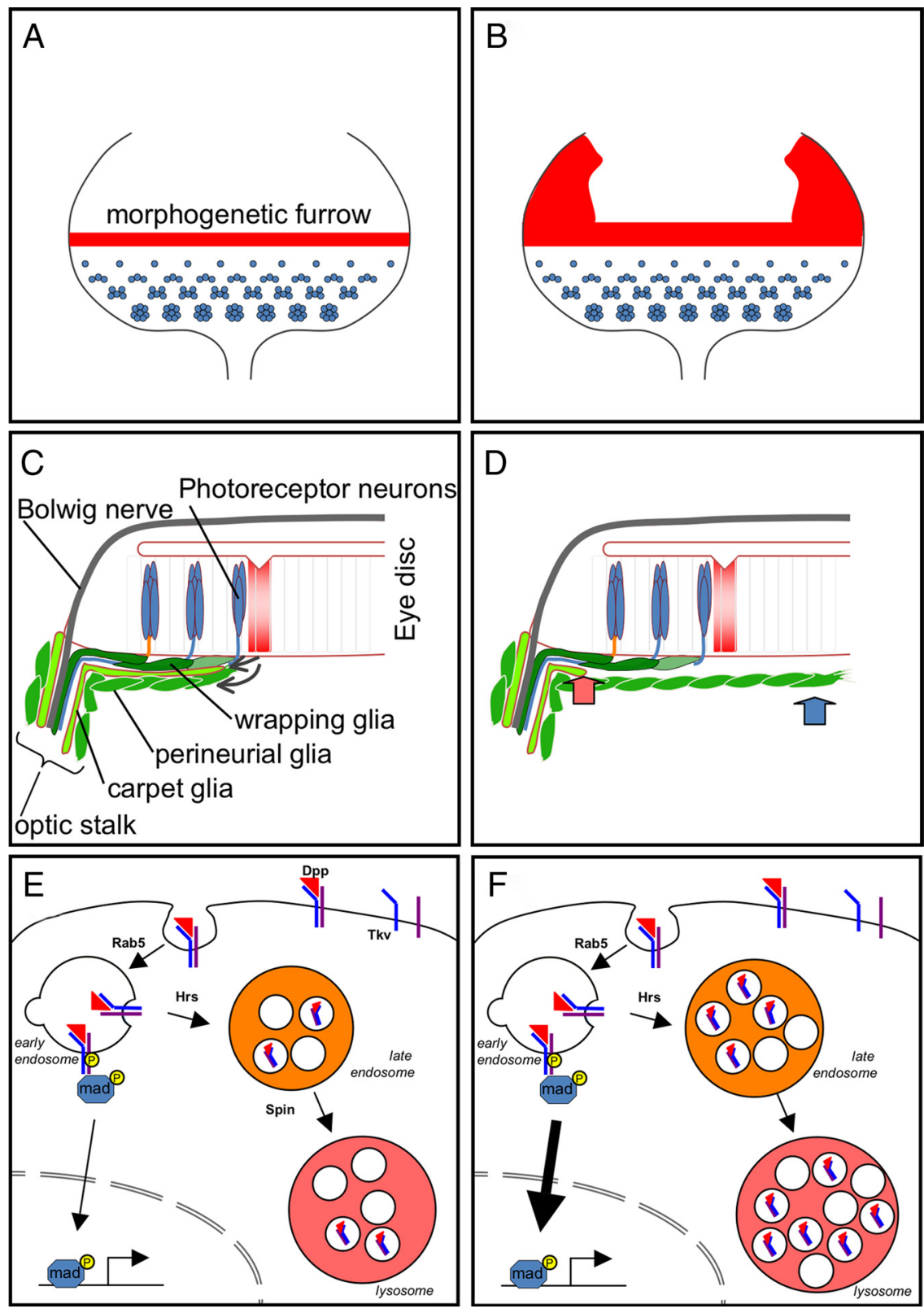

Figure 9. Schematic view on spinster function. Spinster is required to control to coordinate the migration of the retinal glial cells with the growth of the eye imaginal disc. $\boldsymbol{A}$, In wild-type third-instar eye discs, photoreceptor development is initiated in the wake of the morphogenetic furrow, which expresses Dpp (red). $\boldsymbol{B}$, In mutant spinster eye discs, dpp expression is increased in the eye disc (red). C, In the wild-type discs, the eye disc is connected to the brain via the Bolwig nerve and the optic stalk. Eye disc-derived signals control the growth of the carpet cell and the migration of the perineurial glial cells. $\boldsymbol{D}$, In spinster mutants, the carpet glial is of dramatically reduced size (red arrow). In addition, the perineurial glial cells show increased migratory abilities (blue arrow). $\boldsymbol{E}$, Regulation of Dpp signaling in glial cells requires endocytosis and degradation of the activated Dpp receptor Tkv in lysosomes. Activated Dpp receptors are endocytosed in a Rab5-dependent manner. They are then routed to multivesicular bodies (orange) with the help of Hrs. The Spinster protein participates in the maturation of the lysosomes (red). $\boldsymbol{F}$, In spinster mutants, acidic compartments such as lysosomes and late multivesicular bodies accumulate in addition to the observed increased Tkv signaling.

\section{References}

Affolter M, Pyrowolakis G (2006) eIF4A goes beyond translation. Nat Cell Biol 8:1319-1321.

Aigouy B, Van de Bor V, Boeglin M, Giangrande A (2004) Time-lapse and cell ablation reveal the role of cell interactions in fly glia migration and proliferation. Development 131:5127-5138.

Aigouy B, Lepelletier L, Giangrande A (2008) Glial chain migration requires pioneer cells. J Neurosci 28:11635-11641.

Arbouzova NI, Zeidler MP (2006) JAK/STAT signalling in Drosophila: insights into conserved regulatory and cellular functions. Development 133:2605-2616.
Chen Y, Struhl G (1996) Dual roles for patched in sequestering and transducing Hedgehog. Cell 87:553-563.

Chinchore Y, Mitra A, Dolph PJ (2009) Accumulation of rhodopsin in late endosomes triggers photoreceptor cell degeneration. PLoS Genet 5:e1000377.

Choi KW, Benzer S (1994) Migration of glia along photoreceptor axons in the developing Drosophila eye. Neuron 12:423-431.

Dermaut B, Norga KK, Kania A, Verstreken P, Pan H, Zhou Y, Callaerts P, Bellen HJ (2005) Aberrant lysosomal carbohydrate storage accompanies endocytic defects and neurodegeneration in Drosophila benchwarmer. J Cell Biol 170:127-139. 
Dudu V, Bittig T, Entchev E, Kicheva A, Jülicher F, González-Gaitán M (2006) Postsynaptic mad signaling at the Drosophila neuromuscular junction. Curr Biol 16:625-635.

Edenfeld G, Altenhein B, Zierau A, Cleppien D, Krukkert K, Technau G, Klämbt C (2007) Notch and Numb are required for normal migration of peripheral glia in Drosophila. Dev Biol 301:27-37.

Ekas LA, Baeg GH, Flaherty MS, Ayala-Camargo A, Bach EA (2006) JAK/ STAT signaling promotes regional specification by negatively regulating wingless expression in Drosophila. Development 133:4721-4729.

Entchev EV, Schwabedissen A, González-Gaitán M (2000) Gradient formation of the TGF-beta homolog Dpp. Cell 103:981-991.

Ezratty EJ, Bertaux C, Marcantonio EE, Gundersen GG (2009) Clathrin mediates integrin endocytosis for focal adhesion disassembly in migrating cells. J Cell Biol 187:733-747.

Fischer JA, Eun SH, Doolan BT (2006) Endocytosis, endosome trafficking, and the regulation of Drosophila development. Annu Rev Cell Dev Biol 22:181-206.

Franzdóttir SR, Engelen D, Yuva-Aydemir Y, Schmidt I, Aho A, Klämbt C (2009) Switch in FGF signalling initiates glial differentiation in the Drosophila eye. Nature 460:758-761.

González-Gaitán M (2003) Endocytic trafficking during Drosophila development. Mech Dev 120:1265-1282.

Halter DA, Urban J, Rickert C, Ner SS, Ito K, Travers AA, Technau GM (1995) The homeobox gene repo is required for the differentiation and maintenance of glia function in the embryonic nervous system of Drosophila melanogaster. Development 121:317-332.

Hülsmeier J, Pielage J, Rickert C, Technau GM, Klämbt C, Stork T (2007) Distinct functions of $\alpha$-Spectrin and $\beta$-Spectrin during axonal pathfinding. Development 134:713-722.

Hummel T, Attix S, Gunning D, Zipursky SL (2002) Temporal control of glial cell migration in the Drosophila eye requires gilgamesh, hedgehog, and eye specification genes. Neuron 33:193-203.

Jékely G, Rørth P (2003) Hrs mediates downregulation of multiple signalling receptors in Drosophila. EMBO Rep 4:1163-1168.

Jékely G, Sung HH, Luque CM, Rørth P (2005) Regulators of endocytosis maintain localized receptor tyrosine kinase signaling in guided migration. Dev Cell 9:197-207.

Klämbt C (2009) Modes and regulation of glial migration in vertebrates and invertebrates. Nat Rev Neurosci 10:769-779.

Lee BP, Jones BW (2005) Transcriptional regulation of the Drosophila glial gene repo. Mech Dev 122:849-862.

Lee T, Luo L (1999) Mosaic analysis with a repressible cell marker for studies of gene function in neuronal morphogenesis. Neuron 22:451-461.

Lloyd TE, Atkinson R, Wu MN, Zhou Y, Pennetta G, Bellen HJ (2002) Hrs regulates endosome membrane invagination and tyrosine kinase receptor signaling in Drosophila. Cell 108:261-269.

Lu H, Bilder D (2005) Endocytic control of epithelial polarity and proliferation in Drosophila. Nat Cell Biol 7:1232-1239.

Meinertzhagen IA, Hanson TE (1993) The development of the optic lobe. In: The development of Drosophila melanogaster (Bate M, Martinez Arias A, eds), pp 1363-1491. Cold Spring Harbor, NY: Cold Spring Harbor Laboratory.

Miura S, Takeshita T, Asao H, Kimura Y, Murata K, Sasaki Y, Hanai JI, Beppu H, Tsukazaki T, Wrana JL, Miyazono K, Sugamura K (2000) Hgs (Hrs), a FYVE domain protein, is involved in Smad signaling through cooperation with SARA. Mol Cell Biol 20:9346-9355.

Murakami S, Umetsu D, Maeyama Y, Sato M, Yoshida S, Tabata T (2007) Focal adhesion kinase controls morphogenesis of the Drosophila optic stalk. Development 134:1539-1548.

Nakano Y, Fujitani K, Kurihara J, Ragan J, Usui-Aoki K, Shimoda L, Lukacsovich T, Suzuki K, Sezaki M, Sano Y, Ueda R, Awano W, Kaneda M, Umeda M, Yamamoto D (2001) Mutations in the novel membrane protein spinster interfere with programmed cell death and cause neural degeneration in Drosophila melanogaster. Mol Cell Biol 21:3775-3788.
Penton A, Wodarz A, Nusse R (2002) A mutational analysis of dishevelled in Drosophila defines novel domains in the dishevelled protein as well as novel suppressing alleles of axin. Genetics 161:747-762.

Rangarajan R, Gong Q, Gaul U (1999) Migration and function of glia in the developing Drosophila eye. Development 126:3285-3292.

Rangarajan R, Courvoisier H, Gaul U (2001) Dpp and Hedgehog mediate neuron-glia interactions in Drosophila eye development by promoting the proliferation and motility of subretinal glia. Mech Dev 108:93-103.

Sepp KJ, Auld VJ (1999) Conversion of lacZ enhancer trap lines to GAL4 lines using targeted transposition in Drosophila melanogaster. Genetics 151:1093-1101.

Sepp KJ, Schulte J, Auld VJ (2000) Developmental dynamics of peripheral glia in Drosophila melanogaster. Glia 30:122-133.

Silies M, Klämbt C (2010) APC/C(Fzr/Cdh1)-dependent regulation of cell adhesion controls glial migration in the Drosophila PNS. Nat Neurosci 13:1357-1364.

Silies M, Yuva Y, Engelen D, Aho A, Stork T, Klämbt C (2007) Glial cell migration in the eye disc. J Neurosci 27:13130-13139.

Silies M, Yuva-Aydemir Y, Franzdóttir SR, Klämbt C (2010) The eye imaginal disc as a model to study the coordination of neuronal and glial development. Fly (Austin) 4:71-79.

Simonsen A, Cumming RC, Lindmo K, Galaviz V, Cheng S, Rusten TE, Finley KD (2007) Genetic modifiers of the Drosophila blue cheese gene link defects in lysosomal transport with decreased life span and altered ubiquitinated-protein profiles. Genetics 176:1283-1297.

Stenmark H (2009) Rab GTPases as coordinators of vesicle traffic. Nat Rev Mol Cell Biol 10:513-525.

Stork T, Engelen D, Krudewig A, Silies M, Bainton RJ, Klämbt C (2008) Organization and function of the blood-brain barrier in Drosophila. J Neurosci 28:587-597.

Sunio A, Metcalf AB, Krämer H (1999) Genetic dissection of endocytic trafficking in Drosophila using a horseradish peroxidase-bride of sevenless chimera: hook is required for normal maturation of multivesicular endosomes. Mol Biol Cell 10:847-859.

Sweeney ST, Davis GW (2002) Unrestricted synaptic growth in spinster-a late endosomal protein implicated in TGF-beta-mediated synaptic growth regulation. Neuron 36:403-416.

Torroja C, Gorfinkiel N, Guerrero I (2004) Patched controls the Hedgehog gradient by endocytosis in a dynamin-dependent manner, but this internalization does not play a major role in signal transduction. Development 131:2395-2408.

Treisman JE, Rubin GM (1995) wingless inhibits morphogenetic furrow movement in the Drosophila eye disc. Development 121:3519-3527.

Tsai YC, Yao JG, Chen PH, Posakony JW, Barolo S, Kim J, Sun YH (2007) Upd/Jak/STAT signaling represses $w g$ transcription to allow initiation of morphogenetic furrow in Drosophila eye development. Dev Biol 306: $760-771$.

Ulrich F, Heisenberg CP (2009) Trafficking and cell migration. Traffic 10:811-818.

Vanlandingham PA, Ceresa BP (2009) Rab7 regulates late endocytic trafficking downstream of multivesicular body biogenesis and cargo sequestration. J Biol Chem 284:12110-12124.

von Hilchen CM, Beckervordersandforth RM, Rickert C, Technau GM, Altenhein B (2008) Identity, origin, and migration of peripheral glial cells in the Drosophila embryo. Mech Dev 125:337-352.

von Hilchen CM, Hein I, Technau GM, Altenhein B (2010) Netrins guide migration of distinct glial cells in the Drosophila embryo. Development 137:1251-1262.

Wodarz A, Hinz U, Engelbert M, Knust E (1995) Expression of crumbs confers apical character on plasma membrane domains of ectodermal epithelia of Drosophila. Cell 82:67-76.

Wolff T, Ready DF (1993) Pattern formation in the Drosophila retina. In: The development of Drosophila (Bate M, Martinez Arias A, eds), pp 12771325. Cold Spring Harbor, NY: Cold Spring Harbor Laboratory. 